\title{
Regular Airlines Flying towards A Low Cost Strategy
}

\author{
Cristina Félix Pereira (corresponding author) \\ Lusíada University of Lisbon \\ Alameda Padre Álvaro Proença, 8, 5 D, 1500-475 Lisboa \\ Tel: 351-91-446-0033 E-mail: crisflix@gmail.com \\ Felipa Lopes dos Reis (co-author) \\ Aberta University \\ Rua Soldados da India no 10; 1400-340 Lisboa \\ Tel: 351-96-506-2867 E-mail: felipa.reis@net.sapo.pt
}

\begin{abstract}
This article is based on a study that intends to do an embracing analysis of Services Marketing as applied to the air transportation sector.

As a main objective of the study, a Marketing strategy analysis of the national airline - TAP Portugal was carried out, with special emphasis on a new product to conquer the low cost segment.

A qualitative investigation was made with the purpose to better judge the acceptance of low cost products amongst national and foreign airline clients.

It can be concluded that sector competitiveness obliges the regular service companies to adjust their functional model and processes by offering competitive products specially designed for the low cost segment clients. Nevertheless, they can't reduce their services to pure low cost standard because clients expect a minimum level of quality and frills from them.
\end{abstract}

Keywords: Low cost, Strategy, Services marketing, Aviation

\section{Introduction}

In the last years we have seen a very significant evolution in this particular sector of economic activity, redefining business strategies to attend growing global challenges, as well as the need to embrace environmental concerns and a greater urgency in identifying the best approach to cope with all challenges that derive from the global mutation of sector surroundings.

The air transportation market won new dynamics after deregulation, with an increasing transportation offer and competition in the 90's, which was sustained by the developing technology from airplane constructors.

To survive this fierce competition, by the end of the 90's, a great amount of restructuring and association between airliners took place. The eruption of the Afghan and Iraqi conflicts and the continuous terrorist threat contributed largely to the demand slowdown. On the other hand, due to the economic instability, the appearance of low cost airliners was stimulated, which immediately absorbed part of the regular airline's market with very aggressive price competition.

Early in 2009, a global economic crisis had emerged, starting in the USA with the news of the Madoff scandal, which rapidly spread it's consequences to the European economies, triggering a worldwide recession. The aviation sector was quickly impacted by reduction in the demand for air travel. This was another imponderable factor that sharpened the competition that had been continuously stimulated with the increase of fuel prices and the new challenge that the arrival of low cost airlines had brought to the scene.

The typical approach of regular airlines (some of them flag carriers) was resizing and adjust to the notoriously aggressive emergence of a new type of carrier that resumed its service to the mere transportation of the passenger from an origin A to a destination B, where any other service, classified as frills, is charged separately and with inflated value. On-board service, personal check-in, and luggage are not included in the fee as was standard on the traditional regular companies such as KLM, British Airways or TAP Portugal, to name a few.

This new functional model in a deeply transnational sector triggered a new kind of demand, composed by clients that otherwise wouldn't be able to afford air travel, and others very price sensitive that easily renounce to frills in order to save some money.

This strong competition requires an increase in productivity and profitability, which if not achieved can even compromise the airline's survival. 
It is mandatory for airlines to maximize their aircraft's load factor because every empty seat is revenue lost forever due to the service unseparability characteristic. This means that production and consumption of the service (here the air transportation) are simultaneous activities and that specific characteristic of services make storage unfeasible. As we cannot store any kind of service and therefore must sell as much service as we have available, this also give great emphasis to the balance between offer and demand.

To achieve that balance some regulatory techniques like overbooking are used when demand is greater than offer, as a way to avoid the "no-show" impact. On the other hand, when offer is larger than demand, the cost related to overcome installed capacity limitations, forces redimensioning and recalculation resorting eventually to options such as leasing or outsourcing to face demand peaks.

Besides airline's particular strategies it is unthinkable to neglect the analysis of the global market evolution. Globalization induces the alliance initiative between airline's to increase profitability and member's survivability.

TAP Portugal integrates Star Alliance since 2005, which is the biggest alliance currently in operation. In 2009 it consisted of 21 effective airlines and another four candidates.

An Alliance takes advantage of its member's synergies to expand the operating network to a planetary dimension. It's members, in turn, have the corresponding benefits of the enlarged range for their operations that bring more clients and the saving costs due to the common use of resources, the easier coordination of scale, and a much less effort each member must expend to capture clients when compared to isolated operation. A symbiotic dualism takes place that consequently increases the commodity and convenience of the passenger.

The air transport service, being ephemeral and intangible, is experienced as a result of an act or performance. Its intangibility degree is very high but it is not a pure service because of the other tangible services that complement it as is the case of meals served on-board, in-flight entertainment and even airplane comfort conditions.

The overall result of the performed service is the factor that will be measured and evaluated by the client.

Also, the client involvement in this productive process is important for the success of its performance. This client involvement has been taking greater strategic advantage in the process scope. The development of new communication technologies has a fundamental contribution for this evolution. Today it is common to make reservations and payment of air travel tickets using the internet, which avoids the need to go to a counter. Even the check-in at the desk is being slowly transferred to the web channel.

Of course people adhere and easily participate in these tasks because they benefit from more convenience, time and money savings, as well as a lower risk of losing tickets.

Client's involvement in the service is becoming a more active role, therefore any strategic guidance to position an airline must take into account the client point of view, since it will be his/hers opinion that will dictate the final airline company positioning.

Actually each airliner intends to reach not only one segment of clients but identify in the market several groups or segments with common characteristics, needs and consumption profiles, for which distinctive products are created. This strategy can reveal a high degree of competitiveness if the products designed fit each segment's needs, which can be confirmed by their acceptance. The called "halo-costumers" which are positioned in the fringes or borders of the target segment, are very important as they may consider the offer appealing and strengthen the success of the product.

The company must concentrate all efforts on the market segment that covers its potential clients, or in other words, the ones that can be better satisfied. Market segmentation allows airlines to focus in a group of consumers with the same profile and needs, who can percept and react similarly to a specific Marketing strategy.

The best approach is to identify the greatest value to the client as there is a continuous attention and availability to choose the best cost/benefit offer granted by the market. As this is so, the best strategy to apply is the one that bets on a clever differentiation from the concurrence products.

TAP Portugal, the Portuguese flag carrier, being aware of a necessary effective approach to the market which surroundings are complex and highly mutable, readjusted its offer in 2008 spreading it between five distinct products, four of them directed to economic class and the top one for the high class executive. Each of those products integrate a specific value proposal impacted in it's price and adjusted to the target segments identified.

With this strategy, TAP Portugal not only perfected a high return of investment on Business clients offering them a high class service, but also reserved its lower product to compete in the low cost segment, trying to achieve the maximum profitability of the flights. However, this product called "tap discount" is not permanently available, appearing only to help demand regulation purposes and pushing of new destinations. 
The "tap discount" product is reduced to the minimum service the company is willing to offer to passengers, but adds some benefits to the pure low cost product as for instance the IFE (in-flight entertainment) available to all passengers (newspaper/magazines lecture is excluded), meal service, partial accountable miles flown for frequent flyers and free luggage treatment.

The profitability of flights is therefore bypassed and bridged with the effort to maximize the load factor.

\section{Objectives}

For the investigation a qualitative methodology was applied in order to evaluate the adjustment to the objectives of the product "tap discount" and to collect significant information to identify needs and profiles of the clients that had already chosen this product or are eligible, especially the youth segment considered by TAP to be a strategic one. We have analysed the company strategic approach to the market and its marketing-mix, with emphasis on the product "tap discount" while a strategic element to break into low cost segment.

This generic objective was scrutinized to find more specific elements like company notoriety among a client sample from the European Community, the most appreciated factors, needs and wishes of the general clients and also the loyalty of national clients.

\section{Hypotheses}

Two hypotheses had been envisaged and validated with the elaboration of a Marketing Action Plan sustained by the empiric results from this study. Their formulation tried to help solving the problem beneath the appearance of the "tap discount product".

Therefore we have the following hypotheses:

H1: TAP Portugal improves its competitive strategy to the low cost segment, intensifying the differentiation and capture/retention of new clients.

H2: The specific low cost segment product can be an innovative platform to capture new clients.

As we may conclude later on, the particular characteristics of flexibility and minimal price of this product are more suitable to innovation and achieve the necessary differentiation to conquer a new demand.

\section{Investigation Methodology}

Qualitative investigation was the methodology used in this study with the employment of the three possible data collection techniques: inquiry, either by questionnaire or interview, direct observation and documental analysis.

The investigation began with a former interview to the CEO of TAP Portugal that was precious to obtain a high level understanding of the airline company and the holding where it belongs. Present and future strategies were identified, as well as strengths and weaknesses and the relationship with the sector.

In order to deepen and detail the most important aspects, we conducted two more interviews with both the head of Marketing, Communication and Brand Image as well as the head of Strategic Marketing. At the same time we distributed to several first line staff an information-oriented questionnaire whose answers were completed and detailed by the people with better contribution ability.

We made and inquiry by questionnaire to a target population of 80 individuals among whom we extracted a sample of 63 valid answers, and then divided by three distinct panels. Since we applied different sample techniques, (convenient non-random and random stratified), the sample was divided in three distinct panels with different contribution ability and age stratus. In terms of gender $20 \%$ of the sample were composed by women and $80 \%$ were men.

One panel grouped 13 participants from other countries of European Union, which are frequent flyers. The second panel grouped 16 young students since the $9^{\text {th }}$ grade of basic education until the University level, and the last panel was composed by 34 national adults (ages from 20 to 60) with professional activity. The totality of the population was previously filtered to exclude those who had an airliner collaborator in the family aggregate or that hadn't had flight experience in the past three years. With this filtering we wanted to assure the exemption and validity of participations.

The purpose of this sample was trying to identify a few specific objectives like these client's needs and wishes, the notoriety of the company abroad, the most valuable elements of the service performed and the real and potential loyalty degree.

There were some analysis tools used like the analysis of sustainability and accounts reports of the last two years as well as Star Alliance statistics for TAP Portugal.

Additionally we collected evidence concerning direct observation of intra-European flights and also an analisys of the market offer was made to compare prices from regular and low cost airlines as well as web-based operators. 


\section{Study results}

\subsection{Results of the inquiry by questionnaire}

Primary data collected from the questionnaires was analized in the following way:

It was intended that the responses be classified in bottom up order (from 1 to 9 ) according to the most appreciated airliners quoted on the questionnaire. With this information it would be possible to rank and indentify the appreciation of the overall service of a company.

Similarly, we tried to determine the decisive and priority elements that lead to an airline choice. The respondents were asked to manifest their preference in a crescent scale from one to nine points to facilitate an intuitive answering. Finally we represent the values obtained after proper treatment in orderly appearance.

Let's now see the results from the Community panel. Their preferences are often for their flag carriers, but for the set of companies given, KLM and British Airways take advantage, while TAP Portugal appears in $6^{\text {th }}$ place due to the low notoriety in their countries (mainly from the Eastern Europe).

The critical factors when choosing an airline to travel are distinct whether they refer to a regular or low cost carrier. In low cost, clients value deeply the price which is the less meaningful element when choosing a regular carrier to fly with. In this case convenience factors like airport location, direct flights and schedules, take the priority.

If we analyse all results in a consolidated way, the three panels as one single, the price sensitive attitude is the most preponderant factor although the companies' competitive strategies managed to decrease this tendency with a greater appreciation of on-board service and frills.

The young segment have much less experience using this means of transportation but have a formed critical opinion with suggestions and benefit today from greater autonomy and opportunities to travel than the previous generations.

We conclude non-surprisingly that convenience, speed and effectiveness are success critical factors as we live in a society that values time to a great extent. Clients prefer central airports and direct flights or with speedy connections to reduce as much as possible the travelling time. These preferences are not yet strongly defined in the young segment.

Concerning the particular offer of the low cost products, we can conclude the following:

Generally, clients are satisfied with both regular and low cost airlines, but adjust their expectations to the type of service those companies offer. As this is so, if stimulated to make some improvement suggestions, the desire most commonly referred is to have frills in low cost airlines while for regular airlines it is the desire for better service at the same price or the same service quality for the price.

The demand for a quality service is more often expected from a regular carrier then a low cost one, and consequently failure tolerance decreases because of greater expectance with performance, especially with what concerns to punctuality.

Price sensitiveness is preponderant in a low cost service choice, but for the regular service option, service quality is more valued and all differentiating aspects that can psychologically justify the payment of a higher price. This explains the effort of airlines like TAP Portugal in investing on their higher segments (Business or Executive).

It was found that national clients prefer national carriers when comparing to other airlines. The inhabitants from Azores islands do prefer SATA for historical reasons, as this was for a long time the only means of air travel between Azores and the mainland. Nevertheless recommendation of TAP Portugal is unanimous between all national clients that have a big loyalty to the company with $44 \%$ of them having the flag company's frequent flyer card.

Foreign clients are able to show dissatisfaction more easily when board staff don't pay the attention they require, valuing the quick and effective action from service providers. Their preferences were spread among other European carriers due to weak notoriety of TAP in Central Europe enhanced by a poor passenger attendance. Although in countries historically linked to the immigrant flow, (the so called Diaspora), like Luxembourg, France, Germany and Switzerland, the airline presence is recognized and nurtured by the Portuguese community.

Summarizing, it was confirmed the price sensitivity as a primordial and determinant preference on the low cost scope. In second place comes convenience of schedules, direct flights, with the meal service classified as the less important distinctive element.

\subsection{Direct observation results}

Based on direct observation of the service performed by the national carrier, on medium haul, during last year, we observed an improvement in the in-flight entertainment with the television circuit "Taptv" presenting a gestural translation window and promoting cultural activities in most important Portuguese cities included on its contents. 
Flight attendants have a professional attitude although sometimes haughty and distant. Foreign respondents classified their posture as less proficient when compared with service provided by other European flag companies. This aspect shall be considered to have an improvement in regular training sessions for cabin staff, as there have been some comments of disapproval among the Communitarian panel.

The communication from cabin/cockpit crew to passengers is not harmonized and it is left to crew decision whether to give some punctual information to passengers during the flight or strictly follow the initial security advice. We suggest the first approach which can induce an effective perception of attention, and security in the passenger's minds.

Tangible aspects related with cleaning, meal quality and board service reveal as much quality as any other top airlines. Other valuable service elements like punctuality, check-in, and boarding operations were also positively remarked.

\subsection{Results from the market analizys}

The results from multiple offer analisys for various European destinies showed that TAP Portugal is frequently a good commitment choice between convenience factors and price. With Lisbon being it's principal hub of operation, all flights to European capitals are direct (although some times a technical stopover helps to keep the load factor balance), using central airports and detailed managed schedules. In the particular case of a flight to Paris during a long holiday weekend our analysis concluded that the final price was closer to the low cost companies like Ryanair or Easyjet, than other regular flag carriers like Air France, Lufthansa or Iberia, these being the most direct competition in terms of quality of service.

The fact of Lisbon being TAP's central hub of operations facilitates this advantage to direct competition for the intra-Community flights, making it difficult to discover a more appellative and balanced option. Daily flight frequency and destinies can still be improved, but this is already being worked on with the extended offer that the summer of 2009 will bring, reaching Moscow, Helsinki and Warsaw.

\section{Conclusions}

The improvement of communication technologies and massive internet access, facilitate the transfer of services like ticket reservation and check-in and consequently the inherent transferring to the client of the responsibility and active role in the travelling process. A strong bet on web-channel has been worked by TAP Portugal as a strategic opportunity related to distribution and marketing channels.

The "tap discount" product has the minimum possible price the company can offer maintaining it's quality standards and frills, and therefore the leading vision must be to orient the product to new receptive universes and target segments using well structured and innovative advertisement campaigns.

Detailed or significant information about client profiles, especially from the low cost segment is not available. This information including expenditure profiles or need assessment, are essential mechanisms to use in order to identify our product's potential clients. For that purpose the market research studies assume competitive advantage when recognizing the critical success factors. These very important factors are the most relevant variables in differentiation from the competition because they are the most valuable elements for airline clients. They are the elements that will give more benefits to the client and so the most appreciated and valued ones, which make the airline company responsible for the identification of methods, attitudes and actions effective to retrieve clients from the competion.

Answering the formulated hypotheses in the beginning of this study that considered this a potential product to build an innovative platform to capture and retain new clients, whose micro-segmentation would improve the competitive strategy approach to the low cost segment, we found the following:

- the "tap discount" product in addition to it's attractive price, has well dimensioned associated frills;

- It's a strong and convincing product when related to pure low cost offer;

- The promotional window is not permanent but rather activated when there is interest by the company (which is a disadvantage in the client point of view).

- The applied strategy, concentrate the availability of the "tap discount" product in special seasons and for promoting new destinies. Regularly the campaigns are wide-spectrum ranging but are beginning to focus on small niches as was the case of the surfer's promotion on May 2009.

Statistically TAP Portugal have lower load factor values when compared with its direct competitors, and shall try to improve this index through segment and market niche diversification, as well as optimizing the product's temporal availability window. 
Amongst the target segments to capture/retain it's recommended that an effort in the senior, new independent feminine and youth segments must be made. This is sustained by their time and psychological availability to travel in low demand periods, if well convinced to do so. Youngest clients are a future successful and profitable bet with a large period of time to recover investment and an advantageous initiative if we keep in mind that client retention investment is usually less expensive than new client capture.

The company still has a major reactive action as illustrated by the Lisbon-Funchal route promotion implemented just to face Easyjet's penetration. A more pro-active attitude can avoid penetration from competitors to explore latent opportunities.

In order to captivate more clients for all product spectrum offers, more attention must be paid to existing gaps (concerning information) or latent gaps (dealing with flexibility) in the needs of the clients.

Reservation facilities (accommodation, terrestrial transportation, tours, exhibitions, restaurants) coordinated with the travelling plan and in association or partnership can induce the increase of client satisfaction due to greater convenience and a fully relaxed travel with no ultimate surprises in complementary services reservations.

The design of promotional campaigns shall be done in a way that potential clients recognize the motivation they need to be convinced to travel.

The other existing alternatives, either airline direct offer or web-based operators don't threaten the Portuguese company that is capable of offering attractive schedules and prices. This is possible due to a great investment in the yeld management company sector, considered to be a strategic field to work on.

The basilar service provided by airlines has no innovative capacity as it is resumed from transportation from point A to point B. Although, it has additional complementary services called frills this also doesn't have any more elasticity to innovate as they were already too explored. Nevertheless the commercial issues are getting transposed to the scope of the client action, which can take over the selling process via the web channel and be psychologically stimulated with products that can induce the growth in tickets sales.

The only part of the question that can be improved is the set of supplementary services provided before and after the flight in a way that facilitates the overall travelling commodity of the passengers.

\section{References}

ABEYRATNE, Ruwantissa I. R. (2004). Aviation in Crisis. England: Ashgate Publishing Limited.

AEA, Association of European Airlines. (1996). Industry Trends 1996 [S.1.].

AIRBUS, Global Market Forecast. (2000-2019).

BALDWIN, Rodney. (1998). Developing the Future Aviation System. England: Ashgate Publishing Limited.

Giovanni Bisignani, International Air Transport Association Annual Report 2009, 65th Annual General Meeting
Kuala
Lumpur,
June
2009
[Online]:

http://www.iata.org/NR/rdonlyres/A33BC4B3-431B-4690-BE6D788900C8AE3/0/IATAAnnualReport2009.pdf

BARTLETT, Christopher, \& GHOSHAL, Sumantra. (1991). Managing Across Borders. Boston: Harvard Business Press.

GRÖNROOS, Christian. (2007). Service Management and Marketing. $3^{\text {rd }}$ ed. Ed. Wiley. pp.125-127

LEVITT, Theodore. (1991). The Globalization of Market, in: Montgomery, Cynthia A. e Porter, Michael E., Strategy: Seeking and Securing Competitive Advantage. Boston: Harvard Business Review.

LORANGE, Peter, ROOS, Johan. (1992). Strategic Alliances: Formation, Implementation and Evolutions. Cambridge ; Massachusetts ; USA: Blackwell Publishers.

KAY, John. (1996). Globalization of the Skies. Financial Times, June 21.

LESSARD-HÉBERT, Michelle, GOYETTE, Gabriel, \& BOUTIN, Gerald. (1990). Investigação qualitativa Fundamentos e práticas. Editions Agence d'ARC Inc. p.144.

LOVELOCK, Christopher, WIRTZ, Jochen. (2006). Services Marketing: People, Technology, Strategy. $6^{\text {th }}$ ed. Prentice Hall. p10.

MEYER, John R., STRING, John S. (1992). From closed set to open set deregulation: an assessment of U.S. airline industry. Logistics and Transport Review. Vol.28, No.1, pp.1-21

PETERS, Thomas J., WATERMAN Jr. \& Robert H. (1978). In Search of Excellence. Dom Quixote Publishing.

SAUNDERS Mark, LEWIS, Philip, THORNHILL, Adrian. Research Methods for Business Students. $4^{\text {th }}$ ed. Prentice Hall. 
TANEJA, Nawal K. (2002). Driving Airline Business Strategies. England: Ashgate Publishing Limited. pp.10-87 WILLIAMS, George. (1994). The Airline Industry and the Impact of Deregulation. Revised Edition. Avebury Aviation.

YOSHINO, Michael Y., RANGAN \& Srinivasa U. (1995). Strategic Alliances: An Entrepreneurial Approach to Globalization. Boston; Massachusetts : Harvard Business.

ZEITHAML, Valarie A., BITNER, Marie Jo. (1996). Services Marketing. McGraw-Hill International Editions. p. 295

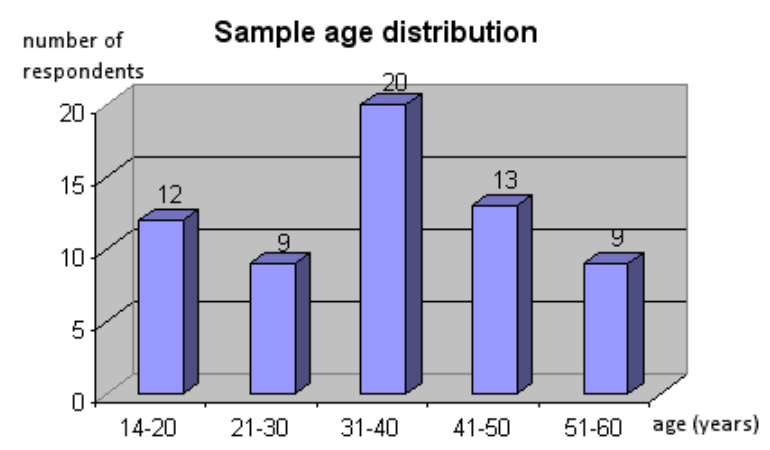

Figure 1. Sample age distribution of the inquiries

This figure illustrates the sample age distribution which was mainly composed with people from thirties to fifties. Accordingly to statistics this is also the most expressive age group of travelers.

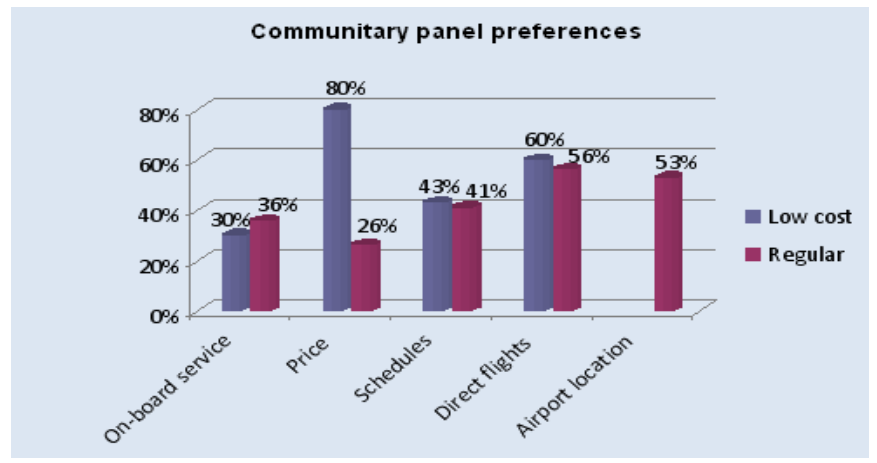

Figure 2. Preferences from the foreign panel sample

This figure illustrates the high price sensitivity in low cost airline's choice. On the other hand, the convenience factors (direct flights, airport location and schedules) are the main factors that lead the option for regular airlines. The airport location is only significant for regular airlines as low cost airlines usually fly to secondary and less central airports.

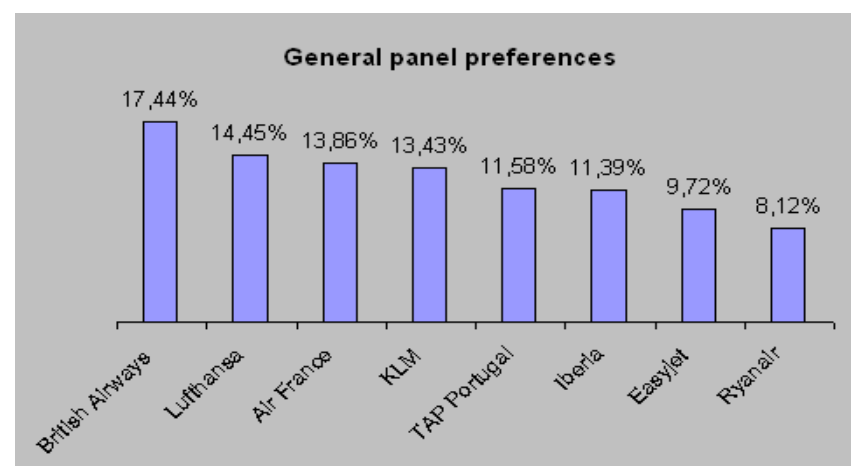

Figure 3. Sample preferences for airline's services

From this figure we can have the sense of airlines position in people's minds. The preferred company in terms of global service is British Airways, and TAP Portugal is positioned amongst the European top companies a step ahead from Iberia. 